\title{
Anti-atherogenic properties of resveratrol: 4-week resveratrol administration associated with serum concentrations of SIRT1, adiponectin, S100A8/A9 and VSMCs contractility in a rat model
}

\author{
MICHAŁ WICIŃSKI, BARTOSZ MALINOWSKI, MATEUSZ M. WĘCLEWICZ, \\ ELŻBIETA GRZEŚK and GRZEGORZ GRZEŚK
}

Department of Pharmacology and Therapeutics, Faculty of Medicine, Collegium Medicum

in Bydgoszcz, Nicolaus Copernicus University, 85-090 Bydgoszcz, Poland

Received October 12, 2016; Accepted December 6, 2016

DOI: $10.3892 /$ etm.2017.4180

\begin{abstract}
Resveratrol (3, 4', 5-trihydroxy-trans-stilbene) is a natural, non-flavonoid polyphenol that exerts protective properties against atherosclerosis-associated endothelial dysfunction and senescence. The present study aimed to assess the influence of resveratrol on vascular contractility and molecular factors including sirtuin-1 (SIRT1), adiponectin and calprotectin (S100A8/A9) that are considered to be important elements of atherogenesis. A total of 17 male rats were divided into a control and treatment group and administered resveratrol or a placebo. Pharmacometrics were performed on an isolated and perfused tail artery. Serum SIRT1, adiponectin and S100A8/A9 levels were quantified using an ELISA assay. The level of SIRT1 in the control and treatment groups at time 0 was 4.26 and $4.45 \mathrm{ng} / \mathrm{ml}$, respectively. SIRT1 in the control and treatment groups following 2 weeks of treatment was 4.59 and $6.86 \mathrm{ng} / \mathrm{ml}$, respectively $(\mathrm{P}<0.05)$ and following 4 weeks of treatment was 4.15 and $6.38 \mathrm{ng} / \mathrm{ml}$, respectively $(\mathrm{P}<0.05)$. The level of adiponectin in the control and treatment groups at time 0 was 1.24 and $1.21 \mathrm{ng} / \mathrm{ml}$, respectively. Following 2 weeks of treatment, the level of adiponectin in the control and treatment groups was 1.22 and $1.2 \mathrm{ng} / \mathrm{ml}$, respectively $(\mathrm{P}>0.05)$ and following 4 weeks of treatment was 1.26 and $1.58 \mathrm{ng} / \mathrm{ml}$, respectively $(\mathrm{P}<0.05)$. The S100A8/A9 level in control and treatment groups at time 0 was 0.39 and $0.33 \mathrm{ng} / \mathrm{ml}$, respectively. The level of S100A8/A9 in control and treatment groups following 2 weeks of treatment was 0.37 and $0.35 \mathrm{ng} / \mathrm{ml}$, respectively ( $\mathrm{P}>0.05)$ and following 4 weeks of treatment was 0.34 and $0.32 \mathrm{ng} / \mathrm{ml}$, respectively $(\mathrm{P}>0.05) . \mathrm{EC}_{50}$ values obtained for
\end{abstract}

Correspondence to: Dr Michał Wiciński, Department of Pharmacology and Therapeutics, Faculty of Medicine, Collegium Medicum in Bydgoszcz, Nicolaus Copernicus University, M. Curie 9, 85-090 Bydgoszcz, Poland

E-mail: wicinski4@wp.pl

Key words: sirtuin-1, adiponectin, S100A8/A9, resveratrol, vascular smooth muscle cells, phosphodiesterase-1 phenylephrine in resveratrol-pretreated arteries were significantly higher than controls in the presence and absence of A7-hydrochloride $(\mathrm{P}<0.05)$. The results of the present study indicate a significant increase in the concentration of SIRT1 and adiponectin in the resveratrol-pretreated group $(\mathrm{P}<0.05)$. S100A8/A9 serum concentrations remained unchanged. Reactivity of resistant arteries was significantly reduced for resveratrol-pretreated vessels and this effect was partially independent of phosphodiesterase (PDE1). Additionally, there was a synergistic interaction observed between resveratrol and the PDE1 inhibitor.

\section{Introduction}

Atherosclerosis is a chronic inflammation of the vascular wall that results in the development of plaques and subsequent stenosis of the arteries $(1,2)$. A number of cytokines are involved in atherosclerosis-related inflammation; these include tumor necrosis factor alpha (TNF- $\alpha$ ), interleukin (IL)-6 and monocyte chemoattractant protein-1 (MCP-1). These factors induce the expression of intercellular adhesion molecule 1 (ICAM-1), vascular cell adhesion molecule 1 (VCAM-1) and E-selectin adhesion molecules and lipid homeostasis $(3,4)$. Other important cytokines responsible for the cross-talk phenomenon that occurs between inflammatory cells and intrinsic factor wall cells are IL-1 $\beta$ and platelet-derived grow th factor cross-reactive material (1). Inflammation associated with atherosclerosis is mediated via the nuclear factor $\kappa \mathrm{B}(\mathrm{NF}-\kappa \mathrm{B})$ signaling pathway, implying that substances inhibiting or activating this factor serve an important role in atherogenesis (5). Sirtuin-1 (SIRT1), adiponectin and calprotectin (S100A8/A9) are characterized as factors able to modulate either the NF- $\kappa \mathrm{B}$ signaling pathway or toll-like receptor 4 (TLR-4) (6-9). Furthermore, they are considered to be important elements for the molecular pathogenesis of atherosclerosis $(4-6,10,11)$. SIRT1 is highly expressed in endothelial cells where it controls angiogenesis through a broad variety of transcriptional regulators, including p53, fork-head box O (FoxO), NF- $\mathrm{B}$, promyelocytic leukemia protein and activated receptor- $\gamma$. SIRT1 serves a crucial role in endothelial homeostasis and it is suggested that overexpression of SIRT1 may contribute to vasoprotection $(12,13)$. In a 
previous experimental study, it was demonstrated that activation of SIRT1 is associated with a reduction in atherosclerotic lesion macrophage content, as well as atherosclerotic lesion size in aortic arches (6). Furthermore, SIRT1 transgenic apolipoprotein E null (apoE ${ }^{-/}$) mice had fewer atherosclerotic lesions, indicating that endothelium-specific SIRT1 overexpression may suppress atherogenesis by influencing endothelial cell survival and function, mediated through regulating the level of nitric oxide synthase (NOS)-3 (14).

The level of adiponectin is negatively associated with visceral fat area and body mass index increase; this explains the marked reduction of adiponectin levels in a number of obese and insulin-resistant states (15). Observational human studies, despite their insufficiency, indicate that low adiponectin levels are associated with cardiometabolic disorders (16). Furthermore, a low level of adiponectin is presented as a risk factor for the occurrence of atherosclerotic diseases (3). Previous studies using animal models provide conclusions that adiponectin possesses anti-atherogenic properties, which inhibit the formation of atherosclerotic lesions, and overexpression of adiponectin protects against atherosclerosis $(4,5)$.

The S100A8/A9 heterodimer protein is formed of the monomers S100A8 and S100A9, belonging to the S100 family. S100A8 and S100A9 are characterized by their ability to interact with numerous effector proteins, mostly in a calcium $\left(\mathrm{Ca}^{2+}\right)$-dependent manner $(17,18)$. The S100A8/A9 complex has the ability to bind to the endothelium, a process enabled by an interaction between S100A9 and heparin sulphate proteoglycans, but also the S100A8/A9 complex with carboxylated $\mathrm{N}$-glycans, expressed by endothelial cells during inflammation (19). The serum level of S100A8/A9 is associated with an early risk of acute coronary syndromes and the severity of coronary artery disease in diabetic individuals. Previous small sub-group studies also indicate that S100A8/A9 may be a marker of subclinical atherosclerosis, as its elevation in serum corresponds with intima media thickness in patients with diabetes but without any history of previous cardiovascular diseases (CVD) (10,11).

Another identified factor in atherogenesis is vascular contractility, as it is considered clinically relevant that arterial hypertension aggravates atherosclerosis (20). Essential hypertension is the consequence of increased peripheral vascular resistance in resistant arteries. Arteries in hypertensive individuals present increased reactivity to contractive stimulus in comparison to healthy individuals, however the exact cause remains unclear $(21,22)$. Hypertension increases oxidative stress in the vascular wall, contributing to changes in metabolism, subsequent endothelium dysfunction and proliferation of vascular smooth muscle cells (VSMCs) (20). Furthermore, hypertension causes an increase in the level of acute-phase proteins that are circulating in the bloodstream, which have been demonstrated to activate the inflammation process through TLR-4 signaling (21).

Structurally, resveratrol belongs to a group of polyphenols that have been described to have a number of beneficial effects on the cardiovascular system and have been proved to be potent activators of SIRT1 and adiponectin (23). Additionally, the present study hypothesized that it may have a regulatory effect on S100A8/A9 in the endothelium. Resveratrol exerts protective properties against atherosclerosis-associated endothelial dysfunction and senescence by upregulating endothelial NOS and SIRT1 (12). Anti-inflammatory features of the aforementioned polyphenol are described as the ability to scavenge free radicals, as well as inhibit the NF- $\mathrm{B}$ signaling pathway (24).

Vasoprotective properties of resveratrol are well documented by in vitro and animal model studies; therefore the present study used a rat model to assess the effect of 4-week oral administration of resveratrol on serum concentrations of SIRT1, adiponectin and S100A8/A9. Another aim of the present study was to determine whether resveratrol contributes to decreased vascular reactivity and define the mechanisms underlying the resveratrol-induced relaxation of VSMCs.

\section{Materials and methods}

Animals. A total of 17 male Wistar rats (Hodowla Zwierząt Laboratoryjnych, Brwinów, Poland) weighing 250-350 g were selected for the study. The rats were maintained in 12-h light and dark cycles at $20-21^{\circ} \mathrm{C}$ and a humidity of $50-60 \%$. Ad libitum access to food and drinking water during the day and night was provided. The rats were randomly grouped into a treatment $(n=9)$ and control group $(n=8)$. The treatment group was administered resveratrol orally for a period of 4 weeks and the control group was administered a placebo (water). Blood sampling for biochemical tests was performed 0,2 and 4 weeks before the initiation of resveratrol pretreatment via catheter placed in femoral vein. Following 4 weeks of resveratrol pretreatment rats were anesthetized with $120 \mathrm{mg} / \mathrm{kg}$ urethane (Honeywell International Inc., Seelze, Germany) intraperitoneally, and subsequently sacrificed by cervical dislocation. The pharmacometric section of the present study was performed on isolated rat-tail artery, as a recognized model of resistance artery (25). The protocol of the present study was approved by the Ethics Committee for Experiments on Animals (University of Technology and Life Sciences, Bydgoszcz, Poland). All experiments were carried out in accordance with the U.S. National Institutes of Health guidelines.

Drugs and solutions. Resveratrol (Tocris Bioscience, Bristol, UK) at a dose of $10 \mathrm{mg} / \mathrm{kg}$ was administered orally through orogastric catheter. Dose was selected based on a previous trial (26). Reagents used during pharmacometric tests included: A-7 hydrochloride [N-(10-Aminodecyl)-5-chloro-1-naphthalenesulfonamide hydrochloride] and Krebs-Henseleit solution [ $\mathrm{NaCl}(71.8 \mathrm{mM})$, $\mathrm{KCl}(4.7 \mathrm{mM}), \mathrm{CaCl}_{2}(1.7 \mathrm{mM}), \mathrm{NaHCO}_{3}(28.4 \mathrm{mM}), \mathrm{MgSO}_{4}$ (2.4 mM), $\mathrm{KH}_{2} \mathrm{PO}_{4}(1.2 \mathrm{mM})$ and glucose $\left.(11.1 \mathrm{mM})\right]$. Resveratrol and A-7 hydrochloride were purchased from Tocris Bioscience (Bristol, UK), and Krebs-Henseleit solution was purchased from Sigma-Aldrich; Merck KGaA (Darmstadt, Germany).

Study design and conduction. The trial was divided in two sections. The first part consisted of the oral pretreatment of rats with $10 \mathrm{mg} / \mathrm{kg}$ resveratrol solution daily (treatment group) or the same volume of water (control group) for 4 weeks. Blood sampling was performed on day 0 and 2 and 4 weeks following the initiation of the trial. Blood was collected into a sample tube containing clotting activator and subsequently 
subjected to centrifugation at room temperature for $15 \mathrm{~min}$ at $160 \mathrm{x} g$. The supernatant was stored at $-86^{\circ} \mathrm{C}$. Serum concentrations of S100A8/A9, SIRT1 and adiponectin were evaluated using a number of commercially available ELISA kits. These were a sirtuin ELISA kit (cat. no. 201-11-1498; Shanghai Sunred Biological Technology Co., Ltd.; Shanghai, China), a calprotectin ELISA kit (cat. no. EIA-5111; DRG International, Inc., Springfield, NJ, USA) and an adiponectin ELISA kit (cat. no. E091-R; Mediagnost GmbH, Reutlingen, Germany).

The procedure for the pharmacometric trial was adapted from a previous study (27). Sections of rat tail arteries (2.5-3.0-cm long), without significant branching, were dissected, subjected to the introduction of a cannula through the proximal section and placed vertically in a 20-ml Multi Chamber Tissue Bath System (TSZ-04; Experimetria Ltd., Budapest, Hungary). Subsequently, the cannula was connected to a perfusion device (Zalimp, Warsaw, Poland) and the artery was strained with $500 \mathrm{mg}$ weight. During the initial part of the assay, the vessel was stabilized in oxygenated Krebs-Henseleit solution (Merck KGaA) at a temperature $37.0^{\circ} \mathrm{C}$ and $\mathrm{pH} 7.4$. Perphusate flow was performed using a peristaltic pump with flow gradually increased from $0.25-1.0 \mathrm{ml} / \mathrm{min}$, until a perfusion pressure between $2-4 \mathrm{kPa}$ was achieved. Artery contraction was induced by injection of phenylephrine (PHE) (Merck KGaA) into the lumen of the vessel. PHE is a full $\alpha 1$-adrenergic receptor agonist, in the control conditions and in the presence of A-7 hydrochloride (Tocris Bioscience). A-7 hydrochloride at a dose of $3 \mu \mathrm{M} / 1$ was selected, as it is a potent calmodulin antagonist that is characterized by the ability to inhibit calmodulin-activated phosphodiesterase (PDE) activity with an $\mathrm{IC}_{50}$ of $3.0 \mu \mathrm{M}$ (28).

Vascular smooth muscle cells contractility was determined as an increase in continuously measured perfusion pressure. Perfusion pressure was measured on BPR-01 and BPR-02 transducers (Experimetria Ltd.) connected to a digital recorder (Graphtec Midi Logger GL820; Grapthec Corp., Yokohama, Japan).

Statistical analysis. Statistical analysis was performed using SPSS version 23.0 software (IBM SPSS, Armonk, NY, USA). The Shapiro-Wilk test was used to determine normal distribution of the investigated variables. To compare the differences between two mean values a one-way analysis of variance test was used. Results were presented as mean \pm standard deviation. $\mathrm{P}<0.05$ was considered to represent a statistically significant difference. Concentration-response curves (CRCs) were calculated according to the van Rossum method (29). The maximal response of tissue $\left(\mathrm{E}_{\max }\right)$ was calculated as a percent of the maximal response for PHE. Half maximal effective concentration $\left(\mathrm{EC}_{50}\right)$ was estimated using classical pharmacologic methods with pD2 as the negative logarithm of the $\mathrm{EC}_{50}$, similarly to previous studies (30). The number of CRCs and $\mathrm{E}_{\max }$ were used in all calculations estimating the statistical significance.

\section{Results}

Effect of resveratrol administration on serum SIRT1 concentration. Initial values of SIRT1 in the control and treatment

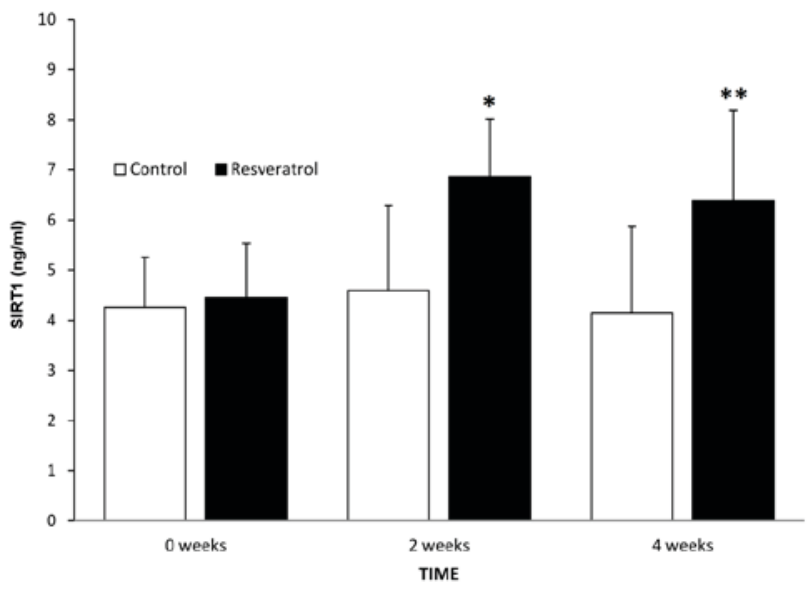

Figure 1. Concentration of SIRT1 in the serum of control and treatment groups, at time 0 and following 2 and 4 weeks of treatment. Data are presented as mean \pm standard deviation. ${ }^{*} \mathrm{P}=0.026$ and ${ }^{* *} \mathrm{P}=0.011$ vs. control. SIRT1, sirtuin-1.

groups were 4.26 and $4.45 \mathrm{ng} / \mathrm{ml}$, respectively $(\mathrm{P}=0.765)$. After 2 weeks, a significant increase was observed compared with the control group $(\mathrm{P}=0.026)$. Values of serum SIRT1 in the control and treatment groups following 2 weeks of treatment were 4.59 and $6.86 \mathrm{ng} / \mathrm{ml}$, respectively. Following 4 weeks there was no increase in the treatment group compared with the treatment group at 2 weeks $(\mathrm{P}=0.547)$, but there was a significant difference between the control and treatment groups following 4 weeks of treatment $(\mathrm{P}=0.011)$. The levels of SIRT1 in the serum of control and treatment groups were 4.15 and $6.38 \mathrm{ng} / \mathrm{ml}$, respectively, at 4 weeks (Fig. 1).

Effect of resveratrol administration on serum adiponectin concentration. The levels of adiponectin in the control and treatment groups at time 0 were 1.24 and $1.21 \mathrm{ng} / \mathrm{ml}$, respectively $(\mathrm{P}=0.827)$. After 2 weeks, there was no difference in adiponectin level in the treatment group compared with the treatment group at time 0 , or with the corresponding control group at 2 weeks $(\mathrm{P}=0.886)$. The levels of serum adiponectin in the control and treatment groups following 2 weeks of treatment were 1.22 and $1.2 \mathrm{ng} / \mathrm{ml}$, respectively. Following 4 weeks, there was a significant increase in the treatment group compared with the treatment group at 2 weeks $(\mathrm{P}=0.036)$ and a significant difference between the control and treatment groups at 4 weeks $(\mathrm{P}=0.026)$. The levels of serum adiponectin in the control and treatment groups following 4 weeks of treatment were 1.26 and $1.58 \mathrm{ng} / \mathrm{ml}$, respectively (Fig. 2).

Effect of resveratrol administration on serum S100A8/A9 concentration. The levels of S100A8/A9 in control and treatment groups at time 0 were 0.39 and $0.33 \mathrm{ng} / \mathrm{ml}$, respectively $(\mathrm{P}=0.935)$. After 2 weeks, there was no significant difference between the treatment group at 2 weeks and the treatment group at time $0(\mathrm{P}=0.811)$, or between this and the control group at 2 weeks $(\mathrm{P}=0.827)$. In the control and treatment groups 2 weeks after the initiation of the study, the levels of serum adiponectin were 0.37 and $0.35 \mathrm{ng} / \mathrm{ml}$, respectively. After 4 weeks, there was no significant difference in the treatment group at this time point compared with the treatment group at 2 weeks $(\mathrm{P}=0.607)$, or with the control group 


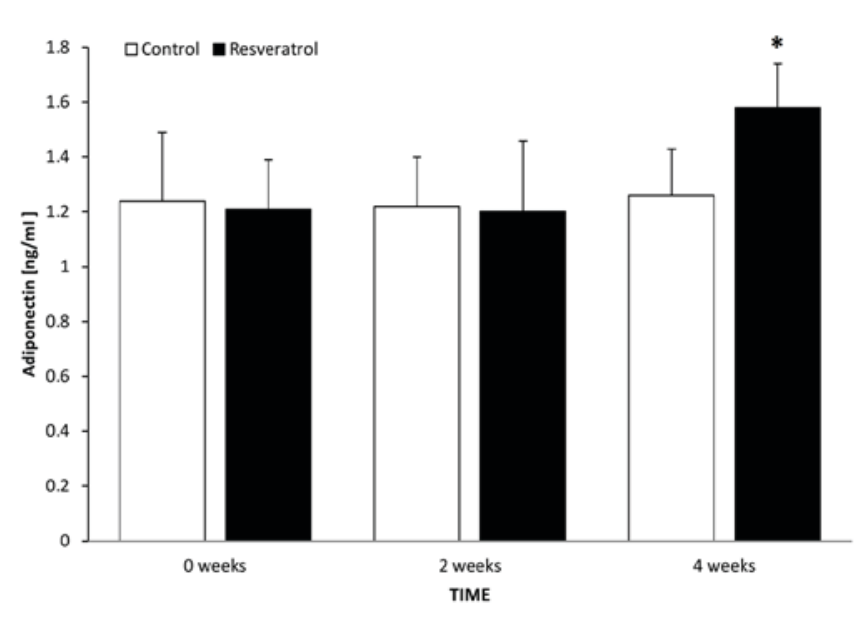

Figure 2. Serum adiponectin concentration in control and treatment groups, at time 0 and following 2 and 4 weeks of treatment. Data are presented as mean \pm standard deviation. ${ }^{*} \mathrm{P}=0.026$ vs. control.

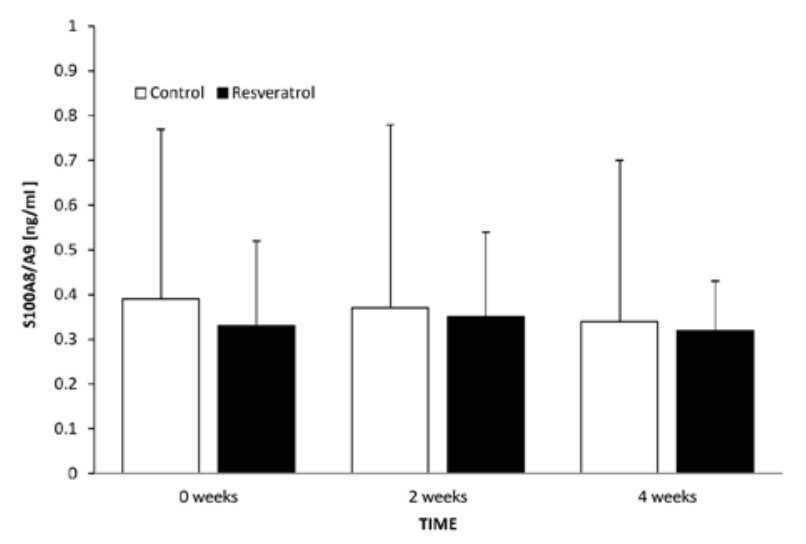

Figure 3. Serum S100A8/A9 concentration in control and treatment groups at time 0 and following 2 and 4 weeks of treatment. Data are presented as mean \pm standard deviation. $\mathrm{P}>0.05$. S110A8/A9, calprotectin.

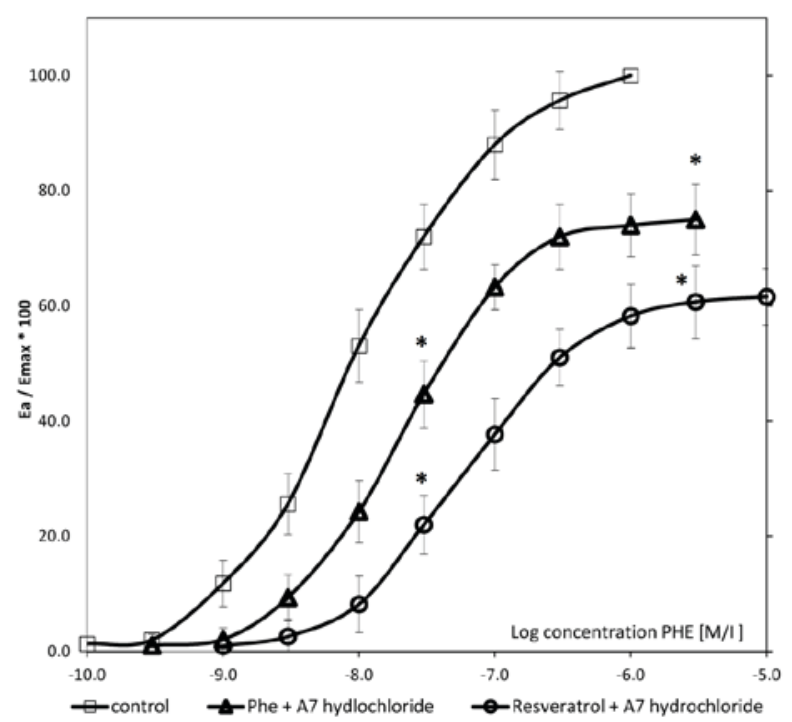

Figure 4. Concentration-response curves in arteries with vascular endothelium obtained for PHE in the resveratrol-pretreated group in the presence of A7-hydrochloride, PHE control and PHE/A7 hydrochloride control. Data are presented as mean \pm standard deviation. For values between $20-80 \%, \mathrm{P}<0.05$. ${ }^{*} \mathrm{P}<0.001$ vs. control. $\mathrm{PHE}$, phenylephrine; $\mathrm{E}_{\max }$, maximal response. at 4 weeks $(\mathrm{P}=0.796)$. The levels of serum adiponectin in the control and treatment groups 4 weeks from the initiation of the study were 0.34 vs. $0.32 \mathrm{ng} / \mathrm{ml}$, respectively (Fig. 3).

Effect of 4-week resveratrol administration on VSMC contractility in the presence of A-7 hydrochloride. CRCs calculated for arteries with endothelium derived from rats following 4 weeks of treatment with resveratrol in the presence of $3 \mu \mathrm{M}$ A7-hydrochloride shifted to the right in both the PHE control and PHE/A7-hydrochloride treatment groups, with the maximal response decrease of $25 \%(\mathrm{P}<0.001)$ and $38.4 \%(\mathrm{P}<0.001)$, respectively. The $\mathrm{EC}_{50}$ value in arteries with vascular endothelium calculated for PHE in rats following 4 weeks of resveratrol administration in the presence of A7-hydrochloride was $7.25 \pm(0.24) \times 10^{-7} \mathrm{M} / \mathrm{l}$, whereas control values for PHE control and PHE/A7-hydrochloride were $3.85( \pm 0.51) \times 10^{-8} \mathrm{M} / 1$ and $7.25 \pm(0.24) \times 10^{-7} \mathrm{M} / 1$, respectively. In both cases, the increase of the $\mathrm{EC}_{50}$ value was statistically significant $(\mathrm{P}<0.001$; Fig. 4; Table I).

Effect of resveratrol on perfusion pressure in the presence and absence of A7 hydrochloride. There was a significant reduction in perfusion pressure in resveratrol-pretreated rat arteries in the presence of A7-hydrochloride compared with the PHE control and PHE/A7-hydrochloride groups ( $\mathrm{P}=0.032$; Fig. 5). Perfusion pressures in PHE control, PHE/A7-hydrochloride and resveratrol-pretreated groups were $88 \pm 10,76 \pm 6$ and $55.2 \pm 12 \mathrm{mmHg}$, respectively.

\section{Discussion}

During in vitro and animal studies, resveratrol previously demonstrated the ability to modulate inflammation in the human body by regulating pro- and anti-inflammatory cytokines (31). Long-term human studies indicate that resveratrol improves the inflammatory status, lipid profile and quality of life of patients undergoing primary prevention of CVD (32-34). Resveratrol inhibits the activation of inflammation-related transcription factors including NF- $\kappa \mathrm{B}$ (33). Resveratrol reduces the serum concentrations of the inflammatory cytokines chemokine ligand 3 , IL-1 $\beta$ and TNF- $\alpha$ (32). In the current study, resveratrol was demonstrated to increase serum concentration levels of factors associated with atherosclerosis, including SIRT1 and adiponectin, but this polyphenol did not significantly affect the S100A8/A9 serum levels $(P>0.05)$. Furthermore, the effect on VSMC contractility was assessed and the mechanisms underlying the reduction of the aforementioned atherosclerosis-associated factors were evaluated. The results of the present study reveal that resveratrol may act as an inhibitor of $\mathrm{Ca}^{2+} /$ calmodulin cyclic nucleotide PDE and contribute to decrease the contractility of vessels.

Resveratrol administration reduces vascular contractility; results of the pharmacological section of this study indicate that resveratrol pretreated rat arteries require higher concentrations of phenylephrine to induce a contraction. Presence of A7-hydrochloride in experimental vessels inhibits $\mathrm{Ca}^{2+} /$ calmodulin cyclic nucleotide PDE1 (28), indicating that resveratrol mechanisms of action are only partially dependent on the aforementioned PDE1 enzyme. The shape of the CRCs 
Table I. Maximal relative response for phenylephrine in relation to the absence and presence of A7-hydrochloride in resveratrol-treated and control groups.

\begin{tabular}{lccc}
\hline Group & $\mathrm{n}^{\mathrm{a}}$ & $\mathrm{E}_{\max }, \%$ & P-value vs. control \\
\hline Control-PHE $(10 \mu \mathrm{M})$ & 12 & 100 & - \\
PHE/A7-hydrochloride $(3 \mu \mathrm{M})$ & 18 & $75.0 \pm 6.1$ & $\mathrm{P}<0.001$ \\
Resveratrol pretreated rats + A7-hydrochloride $(3 \mu \mathrm{M})$ & 22 & $61.6 \pm 4.9$ & $\mathrm{P}<0.001$ \\
\hline
\end{tabular}

Data are presented as mean \pm standard deviation. $\mathrm{P}<0.05$. ${ }^{\mathrm{N}}$ Number of concentration-response curves used for calculations. PHE, phenylephrine; $\mathrm{E}_{\max }$, maximal response.

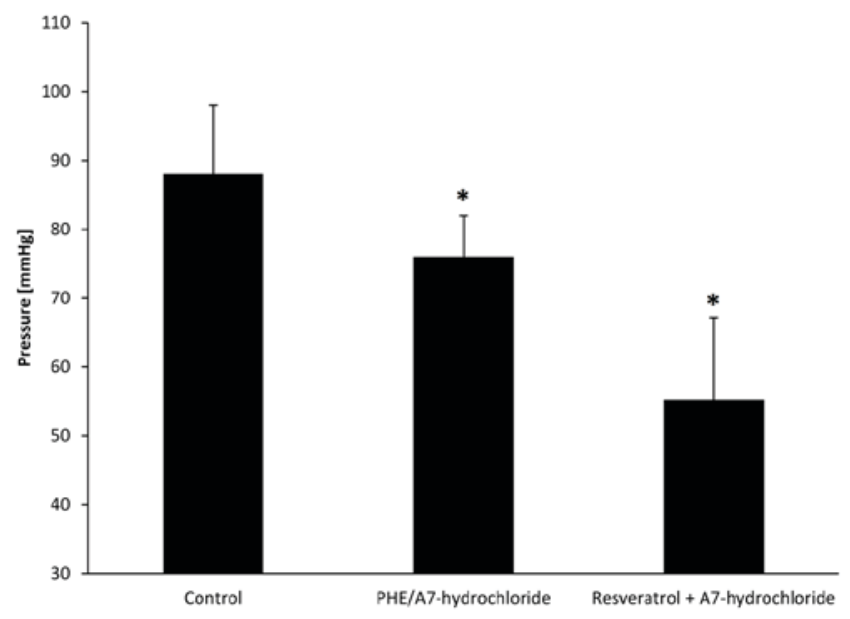

Figure 5. Perfusion pressure in arteries of the resveratrol pretreated group in the presence of A7-hydrochloride, PHE control and PHE/A7 hydrochloride control. Data are presented as mean \pm standard deviation. ${ }^{*} \mathrm{P}<0.05$ vs. control. PHE, phenylephrine.

we acquired indicates that there is a synergistic interaction between resveratrol and PDE1. In the present study, rats that were administered $10 \mathrm{mg} / \mathrm{kg}$ resveratrol daily for 4 weeks had significantly lower vascular reactivity in the presence of A7-hydrochloride $(\mathrm{P}<0.05)$, which indicates that resveratrol inhibits PDE1.

Resveratrol is described by Park et al (35) to be a potent antagonist of cAMP phosphodiesterases (including PDE1-4) that inhibits these enzymes in a concentration-dependent manner. The results of the study demonstrate that resveratrol is potentially a direct inhibitor of PDEs (35), appearing to be consistent with results of the present study. Specifically, conclusions were generated on the basis of the shape of the CRCs obtained. The 'functional reserve' of resveratrol (additional decrease of vessel reactivity in the presence of A7-hydrochloride) suggests that resveratrol may not only induce vasorelaxation via the cyclic guanosine monophosphate (cGMP)-dependent pathways. Kline and Karpinski (36) described the ability of resveratrol to induce NOS-3 in direct and indirect manners through the 5 ' adenosine monophosphate-activated protein kinase (AMPK), SIRT1 and nuclear factor erythroid 2-related factor 2 pathways; but it is also stated that resveratrol acts directly on VSMCs by blocking the L-type calcium channel and inhibiting intracellular $\mathrm{Ca}^{2+}$ release.
Rat model studies indicate that hypertension is associated with the increase of PDE1 expression and activation (37). Inhibition of PDE1 is associated with the decrease of contractile response of the arteries, which is caused by the increase of intracellular concentrations of cGMP in VSMCs. (38). Phosphodiesterase 1C (PDE1C) is potentially implicated in the pathogenesis of atherosclerosis. This subtype of PDE1 is expressed in proliferating smooth muscle cells (39). Inhibition of PDE1C by resveratrol may produce additional beneficial effects due to inhibition of VSMCs proliferation that appears to be one of the crucial elements of atherogenesis (40).

Resveratrol administration increases the serum concentration of SIRT1; previous animal model studies confirm that SIRT1 is a potential target against atherosclerosis and its upregulation serves an important role in molecular mechanisms of endothelial activation $(12,13)$. In the present study, 4-week oral resveratrol treatment in rat models was observed to increase the level of SIRT1 in serum. The results obtained in the current study appear to be compatible with previously conducted trials assessing SIRT1 expression via immunochemistry methods. Thompson et al (41) identified that resveratrol pretreatment of human VSMCs at a dose 3-100 $\mu \mathrm{M}$ significantly increases SIRT1 expression. Kao et al (24) also observed an increase of SIRT1 mRNA in human umbilical vein endothelial cells following pretreatment with different doses of resveratrol $(10-100 \mu \mathrm{M})$.

The molecular mechanisms of SIRT1 action are linked with the prevention of atherosclerosis in a number of experimental models. SIRT1 deacetylates RelA/p65 at K310 and suppresses its binding to naked DNA in human aortic endothelial cells; subsequently this interferes with $\mathrm{NF}-\kappa \mathrm{B}$ signal activation, thereby preventing the expression of genes responsible for synthesis of adhesion molecules, VCAM-1 and ICAM-1 $(8,42)$. Furthermore, previously described NF- $\kappa \mathrm{B}$ signaling pathway suppression by SIRT1 contributes to inhibition of pro-inflammatory cytokine synthesis, including TNF- $\alpha$, IL-1 $\beta$, IL-6 and MCP-1 (6). SIRT1 activation may also suppress angiotensin II type I receptor expression in VSMCs contributing to the mechanism by preventing the increase of blood pressure and vessel contraction (43).

Resveratrol, also known as a polyphenolic SIRT1-activating compound, exhibits vasoprotective properties via SIRT1 dependent pathways (13). The exact mechanism of SIRT1 activation by the aforementioned polyphenol remains unclear, however it is considered that resveratrol activates SIRT1 indirectly $(44,45)$. The induction of AMPK by resveratrol 
appears to be a potential mechanism of SIRT1 activation. AMPK affects the intracellular AMP-to-ATP concentration ratio, which indirectly increases the level of nicotinamide adenine dinucleotide $\left(\mathrm{NAD}^{+}\right)$. Increased $\mathrm{NAD}^{+}$concentrations potentially increase SIRT1 activity, as $\mathrm{NAD}^{+}$is substrate for the aforementioned deacetylase (46). The results of the present study indicate that 4 -week resveratrol pretreatment significantly increases the level of adiponectin in serum $(\mathrm{P}<0.05)$. A shorter period of therapy ( 2 weeks) did not cause a significant change in serum concentrations of adiponectin $(\mathrm{P}>0.05)$. Induction of adiponectin expression by resveratrol was also described in previous animal studies and Rivera et al (26) obtained comparable results. In their study, 8 weeks of $10 \mathrm{mg} / \mathrm{kg}$ resveratrol pretreatment daily caused an increase in the adiponectin serum concentration in obese Zucker rats, although this increase was not observed in lean heterozygous littermates (22). Beaudoin et al (47) demonstrated that 6 weeks of high-dose resveratrol administration $(200 \mathrm{mg} / \mathrm{kg}$ daily) increases the adiponectin concentration and its release from adipose tissue in Zucker rats. Gómez-Zorita et al (48) demonstrated similar results to Beaudoin et al (47) following 6 weeks of $15 \mathrm{mg} / \mathrm{kg}$ resveratrol administration daily. By contrast, Palsamy and Subramanian (49) did not observe a significant increase of plasma adiponectin levels following 30 days of low-dose resveratrol treatment $(5 \mathrm{mg} / \mathrm{kg})$ in a healthy population of Wistar rats. However, an increase was observed in a diabetic population of Wistar rats (49).

The molecular mechanisms of adiponectin involvement in the process of atherogenesis are not fully elucidated. Adiponectin inhibits atherogenesis by suppressing the nuclear translocation of $\mathrm{NF}-\kappa \mathrm{B}$ lowering the endothelial synthesis of pro-inflammatory chemokine IL-8 (7). Additionally, adiponectin attenuates TNF- $\alpha$-induced expression of adhesion molecules on vascular endothelial cells, preventing monocyte adhesion, the initial step of atherogenesis (16).

Resveratrol is considered to upregulate SIRT1, FoxO1 and adiponectin transcription via interconnecting gene modulation pathways (50). Induction of adiponectin may be dependent on a SIRT1-independent mechanism, potentially mediated by downregulation of the phosphoinositide-dependent kinase 1/protein kinase B signaling pathway that leads to FoxO1 activation, or by activation of the AMPK signaling pathway. Resveratrol upregulates adiponectin indirectly by acting on the level of disulfide bond-A oxidoreductase-like protein (23).

Resveratrol administration does not affect S100A8/A9 serum concentrations. Despite the anti-atherogenic properties of resveratrol and the involvement of S100A8/A9 in the process of atherosclerosis, results acquired in the present study indicate that long-term administration of resveratrol in rat models does not influence the S100A8/A9 serum concentration. Furthermore, to the best of our knowledge, similar studies assessing the effect of resveratrol administration on serum levels of S100A8/A9 have not yet been completed.

S100A8/A9 is present in atherosclerotic plaques and has been demonstrated to interact with a number of cell types involved in the atherosclerosis (23). S100A8/A9 acts as a ligand of proatherogenic receptors including TLR-4 and receptors for advanced glycation end products $(8,9)$. In human microvascular endothelial cells, S100A8/A9 induces a specific inflammatory response through an increased transcription of pro-inflammatory IL-8 and chemokine (C-X-C motif) ligand 1 and the decrease of endothelial permeability (19). S100A8/ A9 promotes the binding of inflammatory cells to the vascular endothelium through the upregulation of adhesion molecules VCAM-1 and ICAM-1 and increase of CD11b-CD18 binding capacity of leukocytes to endothelial ICAM-1 (51).

Resveratrol inhibits the activation of $N F-\kappa B$, interferon regulatory factor 3 and activator protein 1 (AP-1) by suppressing the adaptor protein toll receptor-dom ain-containing-adaptor-inducing interferon-beta and TANK-binding kinase (52). AP-1 is potentially required for transcription of S100A8 and S100A9, containing common binding sites for transcription factors, such as AP-1 and CCAAT-enhancer-binding proteins (53). Taken together, resveratrol, via inhibition of AP-1, may have an inhibitory effect on the expression of S100A8 and S100A9; however, this was not confirmed by the decrease in serum concentrations. In conclusion, resveratrol presents the ability to interact with modulators of NF- $\mathrm{BB}$ and TLR-4 that are involved in the atherogenesis (53). The results of the current trial suggest that long-term resveratrol administration may improve the atherosclerosis. Nonetheless, pre-clinical trials need to be followed by long-term human studies to confirm the anti-atherogenic properties of resveratrol.

\section{Acknowledgements}

The present study was funded from a statutory grant (grant no. 632) from the Department of Pharmacology and Therapeutics, Faculty of Medicine, Collegium Medicum in Bydgoszcz, Nicolaus Copernicus University, Torun, Poland.

\section{References}

1. Libby P: Inflammation in atherosclerosis. Arterioscler Thromb Vasc Biol 32: 2045-2051, 2012.

2. Hansson GK and Hermansson A: The immune system in atherosclerosis. Nat Immunol 12: 204-212, 2011.

3. Shimada K, Miyazaki T and Daida H: Adiponectin and atherosclerotic disease. Clin Chim Acta 344: 1-12, 2004.

4. Freitas Lima LC, Braga VA, do Socorro de França Silva M, Cruz JC, Sousa Santos SH, de Oliveira Monteiro MM and Balarini CM: Adipokines, diabetes and atherosclerosis: An inflammatory association. Front Physiol 6: 304, 2015.

5. Wang X, Chen Q, Pu H, Wei Q, Duan M, Zhang C, Jiang T, Shou X, Zhang J and Yang Y: Adiponectin improves NF- $\kappa \mathrm{B}$-mediated inflammation and abates atherosclerosis progression in apolipoprotein E-deficient mice. Lipids Health Dis 15: 33, 2016.

6. Chen YX, Zhang M, Cai Y, Zhao Q and Dai W: The Sirt1 activator SRT1720 attenuates angiotensin II-induced atherosclerosis in apoE $\%$ mice through inhibiting vascular inflammatory response. Biochem Biophys Res Commun 465: 732-738, 2015.

7. Kobashi C, Urakaze M, Kishida M, Kibayashi E, Kobayashi H, Kihara S, Funahashi T, Takata M, Temaru R, Sato A, et al: Adiponectin inhibits endothelial synthesis of interleukin-8. Circ Res 97: 1245-1252, 2005.

8. Michelsen KS, Wong MH, Shah PK, Zhang W, Yano J, Doherty TM, Akira S, Rajavashisth TB and Arditi M: Lack of Toll-like receptor 4 or myeloid differentiation factor 88 reduces atherosclerosis and alters plaque phenotype in mice deficient in apolipoprotein E. Proc Natl Acad Sci USA 101: 10679-10684, 2004.

9. Gebhardt C, Németh J, Angel P and Hess J: S100A8 and S100A9 in inflammation and cancer. Biochem Pharmacol 72: 1622-1631, 2006.

10. Schiopu A and Cotoi OS: S100A8 and S100A9: DAMPs at the crossroads between innate immunity, traditional risk factors, and cardiovascular disease. Mediators Inflamm 2013: 828354, 2013. 
11. Altwegg LA, Neidhart M, Hersberger M, Müller S, Eberli FR, Corti R, Roffi M, Sütsch G, Gay S, von Eckardstein A, et al: Myeloid-related protein 8/14 complex is released by monocytes and granulocytes at the site of coronary occlusion: A novel, early, and sensitive marker of acute coronary syndromes. Eur Heart J 28: 941-948, 2007.

12. Ota H, Eto M, Ogawa S, Iijima K, Akishita M and Ouchi Y: SIRT1/eNOS axis as a potential target against vascular senescence, dysfunction and atherosclerosis. J Atheroscler Thromb 17: 431-435, 2010.

13. Brandes RP: Activating SIRT1: A new strategy to prevent atherosclerosis? Cardiovasc Res 80: 163-164, 2008.

14. Zhang QJ, Wang Z, Chen HZ, Zhou S, Zheng W, Liu G, Wei YS, Cai H, Liu DP and Liang CC: Endothelium-specific overexpression of class III deacetylase SIRT1 decreases atherosclerosis in apolipoprotein E-deficient mice. Cardiovasc Res 80: 191-199, 2008.

15. Okauchi Y, Kishida K, Funahashi T, Noguchi M, Ogawa T, Ryo M, Okita K, Iwahashi H, Imagawa A, Nakamura T, et al: Changes in serum adiponectin concentrations correlate with changes in BMI, waist circumference, and estimated visceral fat area in middle-aged general population. Diabetes Care 32: e122, 2009.

16. Lim S, Quon MJ and Koh KK: Modulation of adiponectin as a potential therapeutic strategy. Atherosclerosis 233: 721-728, 2014.

17. Korndörfer IP, Brueckner F and Skerra A: The crystal structure of the human (S100A8/S100A9)2 heterotetramer, calprotectin, illustrates how conformational changes of interacting alpha-helices can determine specific association of two EF-hand proteins. J Mol Biol 370: 887-898, 2007.

18. Donato R: Intracellular and extracellular roles of S100 proteins Microsc Res Tech 60: 540-551, 2003.

19. Viemann D, Strey A, Janning A, Jurk K, Klimmek K, Vogl T, Hirono K, Ichida F, Foell D, Kehrel B, et al: Myeloid-related proteins 8 and 14 induce a specific inflammatory response in human microvascular endothelial cells. Blood 105: 2955-2962, 2005.

20. Alexander RW: Theodore Cooper Memorial Lecture Hypertension and the pathogenesis of atherosclerosis. Oxidative stress and the mediation of arterial inflammatory response: A new perspective. Hypertension 25: 155-161, 1995.

21. Bomfim GF, Dos Santos RA, Oliveira MA, Giachini FR, Akamine EH, Tostes RC, Fortes ZB, Webb RC and Carvalho MH Toll-like receptor 4 contributes to blood pressure regulation and vascular contraction in spontaneously hypertensive rats. Clin Sci (Lond) 122: 535-543, 2012

22. Doyle AE and Fraser JR: Vascular reactivity in hypertension. Circ Res 9: 755-761, 1961

23. Wang A, Liu M, Liu X, Dong LQ, Glickman RD, Slaga TJ, Zhou Z and Liu F: Up-regulation of adiponectin by resveratrol: The essential roles of the Akt/FOXO1 and AMP-activated protein kinase signaling pathways and DsbA-L. J Biol Chem 286 : 60-66, 2011.

24. Kao CL, Chen LK, Chang YL, Yung MC, Hsu CC, Chen YC, Lo WL, Chen SJ, Ku HH and Hwang SJ: Resveratrol protects human endothelium from $\mathrm{H}(2) \mathrm{O}(2)$-induced oxidative stress and senescence via SirT1 activation. J Atheroscler Thromb 17: 970-979, 2010.

25. Grześk G, Kozinski M, Tantry US, Wicinski M, Fabiszak T, Navarese EP, Grzesk E, Jeong YH, Gurbel PA and Kubica J: High-dose, but not low-dose, aspirin impairs anticontractile effect of ticagrelor following ADP stimulation in rat tail artery smooth muscle cells. Biomed Res Int 2013: 928271, 2013.

26. Rivera L, Morón R, Zarzuelo A and Galisteo M: Long-term resveratrol administration reduces metabolic disturbances and lowers blood pressure in obese Zucker rats. Biochem Pharmacol 77: 1053-1063, 2009

27. Grześk G, Wiciński M, Malinowski B, Grześk E, Manysiak S, Odrowąż-Sypniewska G, Darvish N and Bierwagen M: Calcium blockers inhibit cyclosporine A-induced hyperreactivity of vascular smooth muscle cells. Mol Med Rep 5: 1469-1474, 2012.

28. Itoh $\mathrm{H}$ and Hidaka $\mathrm{H}$ : Direct interaction of calmodulin antagonists with $\mathrm{Ca} 2+/$ calmodulin-dependent cyclic nucleotide phosphodiesterase. J Biochem 96: 1721-1726, 1984.

29. Grześk E, Malinowski B, Wiciński M, Szadujkis-Szadurska K, SinjabTA,ManysiakS,TejzaB,SłupskiM,Odrowąż-SypniewskaG and Grześk G: Cyclosporine-A, but not tacrolimus significantly increases reactivity of vascular smooth muscle cells. Pharmacol Rep 68: 201-205, 2016.
30. Grześk E, Szadujkis-Szadurska K, Wiciński M, Malinowski B, Sinjab TA, Tejza B, Pujanek M, Janiszewska E, Kopczyńska A and Grześk G: Effect of 2,4,6-trimethyl-N-[3-(trifluoromethyl) phenyl]benzene-sulfonamide on calcium influx in three contraction models. Biomedical Rep 4: 117-121, 2016.

31. Gupta SC, Tyagi AK, Deshmukh-Taskar P, Hinojosa M, Prasad S and Aggarwal BB: Downregulation of tumor necrosis factor and other proinflammatory biomarkers by polyphenols. Arch Biochem Biophys 559: 91-99, 2014.

32. Tomé-Carneiro J, Gonzálvez M, Larrosa M, Yáñez-Gascón MJ, García-Almagro FJ, Ruiz-Ros JA, Tomás-Barberán FA, García-Conesa MT and Espín JC: Resveratrol in primary and secondary prevention of cardiovascular disease: A dietary and clinical perspective. Ann N Y Acad Sci 1290: 37-51, 2013.

33. Tomé-Carneiro J, Gonzálvez M, Larrosa M, Yáñez-Gascón MJ, García-Almagro FJ, Ruiz-Ros JA, Tomás-Barberán FA, García-Conesa MT and Espín JC: Grape resveratrol increases serum adiponectin and downregulates inflammatory genes in peripheral blood mononuclear cells: A triple-blind, placebo-controlled, one-year clinical trial in patients with stable coronary artery disease. Cardiovasc Drugs Ther 27: 37-48, 2013.

34. Militaru C, Donoiu I, Craciun A, Scorei ID, Bulearca AM and Scorei RI: Oral resveratrol and calcium fructoborate supplementation in subjects with stable angina pectoris: Effects on lipid profiles, inflammation markers and quality of life. Nutrition 29: 178-183, 2013.

35. Park SJ, Ahmad F, Philp A, Baar K, Williams T, Luo H, Ke H, Rehmann H, Taussig R, Brown AL, et al: Resveratrol ameliorates aging-related metabolic phenotypes by inhibiting cAMP phosphodiesterases. Cell 148: 421-433, 2012.

36. Kline LW and Karpinski E: The Resveratrol-induced Relaxation of Cholecystokinin Octapeptide- or KCl-induced Tension in Male Guinea Pig Gallbladder Strips Is Mediated Through L-type Ca2+Channels. J Neurogastroenterol Motil 21: 62-68, 2015.

37. Evgenov OV, Busch CJ, Evgenov NV, Liu R, Petersen B, Falkowski GE, Petho B, Vas A, Bloch KD, Zapol WM and Ichinose F: Inhibition of phosphodiesterase 1 augments the pulmonary vasodilator response to inhaled nitric oxide in awake lambs with acute pulmonary hypertension. Am J Physiol Lung Cell Mol Physiol 290: L723-L729, 2006.

38. Giachini FR, Lima VV, Carneiro FS, Tostes RC and Webb RC: Decreased cGMP level contributes to increased contraction in arteries from hypertensive rats: Role of phosphodiesterase 1. Hypertension 57: 655-663, 2011.

39. Rybalkin SD, Rybalkina I, Beavo JA and Bornfeldt KE: Cyclic nucleotide phosphodiesterase $1 \mathrm{C}$ promotes human arterial smooth muscle cell proliferation. Circ Res 90: 151-157, 2002

40. Bischoff E: Potency, selectivity, and consequences of nonselectivity of PDE inhibition. Int J Impot Res 16 (Suppl 1): S11-S14, 2004.

41. Thompson AM, Martin KA and Rzucidlo EM: Resveratrol induces vascular smooth muscle cell differentiation through stimulation of SirT1 and AMPK. PLoS One 9: e85495, 2014.

42. Stein S, Schäfer N, Breitenstein A, Besler C, Winnik S, Lohmann C, Heinrich K, Brokopp CE, Handschin C, Landmesser U, et al: SIRT1 reduces endothelial activation without affecting vascular function in $\mathrm{ApoE}^{-/}$mice. Aging (Albany NY) 2: 353-360, 2010.

43. Miyazaki R, Ichiki T, Hashimoto T, Inanaga K, Imayama I, Sadoshima J and Sunagawa K: SIRT1, a longevity gene, downregulates angiotensin II type 1 receptor expression in vascular smooth muscle cells. Arterioscler Thromb Vasc Biol 28: 1263-1239, 2008.

44. Higashida K, Kim SH, Jung SR, Asaka M, Holloszy JO and Han DH: Effects of resveratrol and SIRT1 on PGC-1 $\alpha$ activity and mitochondrial biogenesis: A reevaluation. PLoS Biol 11: e1001603, 2013.

45. Li J, Feng L, Xing Y, Wang Y, Du L, Xu C, Cao J, Wang Q, Fan S, Liu Q and Fan F: Radioprotective and antioxidant effect of resveratrol in hippocampus by activating Sirt1. Int J Mol Sci 15: 5928-5939, 2014

46. Cantó C, Gerhart-Hines Z, Feige JN, Lagouge M, Noriega L, Milne JC, Elliott PJ, Puigserver P and Auwerx J: AMPK regulates energy expenditure by modulating $\mathrm{NAD}^{+}$metabolism and SIRT1 activity. Nature 458: 1056-1060, 2009.

47. Beaudoin MS, Snook LA, Arkell AM, Simpson JA, Holloway GP and Wright DC: Resveratrol supplementation improves white adipose tissue function in a depot-specific manner in Zucker diabetic fatty rats. Am J Physiol Regul Integr Comp Physiol 305: R542-R551, 2013. 
48. Gómez-Zorita S, Fernández-Quintela A, Lasa A, Hijona E, Bujanda L and Portillo MP: Effects of resveratrol on obesity-related inflammation markers in adipose tissue of genetically obese rats. Nutrition 29: 1374-1380, 2013.

49. Palsamy P and Subramanian S: Resveratrol protects diabetic kidney by attenuating hyperglycemia-mediated oxidative stress and renal inflammatory cytokines via Nrf2-Keap1 signaling. Biochim Biophys Acta 1812: 719-731, 2011.

50. Costa Cdos S, Rohden F, Hammes TO, Margis R, Bortolotto JW, Padoin AV, Mottin CC and Guaragna RM: Resveratrol upregulated SIRT1, FOXO1, and adiponectin and downregulated PPAR $\gamma 1-3$ mRNA expression in human visceral adipocytes. Obes Surg 21: 356-361, 2011.

51. Newton RA and Hogg N: The human S100 protein MRP-14 is a novel activator of the beta 2 integrin Mac-1 on neutrophils. J Immunol 160: 1427-1435, 1998.
52. Kim MH, Yoo DS, Lee SY, Byeon SE, Lee YG, Min T, Rho HS, Rhee MH, Lee J and Cho JY: The TRIF/TBK1/IRF-3 activation pathway is the primary inhibitory target of resveratrol, contributing to its broad-spectrum anti-inflammatory effects. Pharmazie 66: 293-300, 2011.

53. Sunahori K, Yamamura M, Yamana J, Takasugi K, Kawashima M, Yamamoto H, Chazin WJ, Nakatani Y, Yui S and Makino H: The S100A8/A9 heterodimer amplifies proinflammatory cytokine production by macrophages via activation of nuclear factor kappa B and p38 mitogen-activated protein kinase in rheumatoid arthritis. Arthritis Res Ther 8: R69, 2006. 